\title{
Questionnaire-based survey on the prevalence of medication-overuse headache in Japanese one city-Itoigawa study
}

\author{
Masahito Katsuki ${ }^{1}$ (C) Chinami Yamagishi ${ }^{2} \cdot$ Yasuhiko Matsumori $^{3} \cdot$ Akihito Koh $^{1} \cdot$ Shin Kawamura ${ }^{1}$. \\ Kenta Kashiwagi ${ }^{4} \cdot$ Tomohiro Kito $^{5} \cdot$ Akio Entani $^{6} \cdot$ Toshiko Yamamoto $^{7} \cdot$ Takashi Ikeda $^{2} \cdot$ Fuminori Yamagishi $^{8}$
}

Received: 10 November 2021 / Accepted: 14 December 2021 / Published online: 19 January 2022

(c) Fondazione Società Italiana di Neurologia 2021

\begin{abstract}
Objective The medication-overuse headache (MOH) prevalence has not been investigated in a general Japanese population. We performed questionnaire-based survey and revealed $\mathrm{MOH}$ prevalence and its characteristics. We also performed clustering to obtain insight for $\mathrm{MOH}$ subgrouping.

Methods In this cross-sectional study, the 15-64-year-old population was investigated in Itoigawa during their COVID-19 vaccination under the national policy. MOH was defined as $\geq 15$ days/month plus self-report of use of pain medications $\geq 10$ or 15 days/month in the last 3 months. Ward method and k-means + + were used to perform clustering MOH patients.

Results Among 5865 valid responses, $\mathrm{MOH}$ prevalence was $2.32 \%$. MOH was common among females and the middleaged. Combination-analgesic is the most overused as $50 \%$. MOH had aggravation by routine physical activity, moderate or severe pain, and migraine-like, compared to non-MOH. The $136 \mathrm{MOH}$ patients could be grouped into 3 clusters. Age and frequency of acute medication use were essential factors for clustering.

Conclusions This is the first study of MOH prevalence in Japan. Most MOH characteristics were similar to previous reports worldwide. Public awareness of proper headache treatment knowledge is still needed. Clustering results may be important for subtype grouping from a social perspective apart from existing clinical subtypes.
\end{abstract}

Keywords Artificial intelligence (AI) $\cdot$ Chronic headache $\cdot$ Clustering $\cdot$ Epidemiology $\cdot$ Medication-overuse headache $(\mathrm{MOH}) \cdot$ Migraine

Masahito Katsuki

ktk1122nigt@gmail.com

1 Department of Neurosurgery, Itoigawa General Hospital, Itoigawa, Niigata 941-0006, Japan

2 Department of Health Promotion, Itoigawa City, Itoigawa, Niigata 941-8501, Japan

3 Sendai Headache and Neurology Clinic, Sendai, Miyagi 982-0014, Japan

4 Department of Neurology, Itoigawa General Hospital, Itoigawa, Niigata 941-0006, Japan

5 Department of Neurosurgery, Nou National Health Insurance Clinic, Itoigawa, Niigata 949-1331, Japan

6 Department of Internal Medicine, Itoigawa General Hospital, Itoigawa, Niigata 941-0006, Japan

7 Department of Nursing, Itoigawa General Hospital, Itoigawa, Niigata 941-0006, Japan

8 Department of Surgery, Itoigawa General Hospital, Itoigawa, Niigata 941-0006, Japan

\section{Introduction}

Headache is a widespread and costly public health problem $[1,2]$. Migraine and tension-type headache (TTH) are included as primary headaches in the International Classification of Headache Disorders 3rd edition (ICHD-3) [3], and they are the main types of primary headaches. In Japan, the overall prevalence of migraine is $6.0-8.4 \%$, and $74.2 \%$ of them complain that migraine headache impairs their daily activity significantly [4-7]. A previous study shows that Japanese migraine patients have an incremental burden compared to non-migraine patients in terms of decreased health-related quality of life, impaired productivities, more healthcare providers visits, and higher indirect costs [8]. Also, about 15-20\% of Japanese people have TTH, and 22.4-29.2\% complained that TTH disturbed their performances $[7,9,10]$. However, only $2.7 \%$ of the migraine patients consult a medical facility regularly [6], and 59.4\% of the primary headache patients had never consulted a 
physician about their headaches [9]. Therefore, most headache patients presumably manage the pains by taking overthe-counter (OTC) medicines [7]. Besides, if the headache patients consult doctors, only neuroimaging is conducted to exclude emergent or organic diseases, and the diagnosis for detailed primary headache and its treatment are inadequate. Even when the doctors diagnose primary headaches, their treatment knowledge is unsatisfactory, leading to patient dissatisfaction [7]. These insufficient and inadequate headache medical resources and OTC medicine use may lead to medication-overuse headache (MOH) development [11].

$\mathrm{MOH}$ was one form of headache and was ranked 20th in 2015 of the Global Burden of Disease [12]. In the latest GBD analyses published in 2019, MOH was not listed as a separate condition but as a contributor to the burden of migraine and TTH [2]. MOH is defined according to the diagnostic criteria in ICHD-3: Frequency of headache (15 or more days per month in the last 3 months), frequent intake of pain medications (10 or 15 days per month, depending on medicine type and combination), and not better accounted for by another ICHD-3 diagnosis [3]. Adequate use of acute and prophylactic medication for headache may prevent $\mathrm{MOH}$ development [11]. Therefore, public awareness of proper headache treatment knowledge to healthcare providers and patients is still needed [13].

The MOH prevalence has not been well studied. $\mathrm{MOH}$ occurs in $0.5-7.2 \%$ of the total population (median estimate of $1 \%-2 \%$ ), depending on the country and age range of the subjects. MOH most commonly affects women, with a peak incidence in 50-60 years of age [14]. While there are some reports worldwide on $\mathrm{MOH}$ prevalence, there are no reports on Japanese $\mathrm{MOH}$ prevalence and its characteristics. Therefore, we perform a questionnaire-based study to investigate the Japanese $\mathrm{MOH}$ prevalence among the working-age population because they are working and should avoid the headache burden.

As MOH subtypes, ICHD-3 defined MOH subtypes according to the overused medications [3]. The difference between subtypes was investigated [15], which contributes to more clearly defining the clinical picture of a poorly delineated $\mathrm{MOH}$. To clarify the social background and clinical profile of the $\mathrm{MOH}$ patients aside from the medication type defined in ICHD-3, we preliminarily used clustering methods to group the $\mathrm{MOH}$ patients by some variables. We used hierarchical clustering by the classical Ward method [16] and non-hierarchical clustering using k-means ++ [17], one of the types of artificial intelligence.

The primary objectives of this project were to study $\mathrm{MOH}$ prevalence in the general Japanese population. The secondary objective was to identify the characteristics of $\mathrm{MOH}$ respondents compared to headache without MO respondents. The third objective was to identify the hypothetical $\mathrm{MOH}$ subgroups using clustering methods.

\section{Materials and methods}

\section{Study population and survey procedure}

We performed this cross-sectional questionnaire-based study during the 15-min waiting period after the COVID-19 vaccination, with sufficient infection control like sterilization. The Japanese vaccination law was revised on December 2, 2020, and all the Japanese people have received the COVID19 vaccination as a duty of effort. In Itoigawa city, the vaccination started in June 2021, and the first-time vaccinations were completed in October 2021. There were 2 large vaccination sites (Itoigawa General Hospital and Nou National Health Insurance Clinic) and 11 other small vaccination sites, such as clinics. We performed this questionnaire at the 2 large vaccination sites. The citizens could select where they undergo vaccination.

We handed the questionnaire sheet and a pen to the citizens who underwent first-time vaccination, and they read it and wrote down the answers. Valid responses were those that filled in all the items in the questionnaire sheet. People who could not understand the questionnaire due to dementia, psychiatric disorder, and mental retardation and who indicated that they did not want to participate in this study were excluded. The questionnaire sheets with one or more blank answers were also excluded from this study. People aged 15-64 as the working-age population was analyzed. Among those, $\mathrm{MOH}$ prevalence and its relationship to the items in the questionnaire sheet were investigated.

\section{Items in the questionnaire sheet}

The questionnaire sheet consisted of the following 13 items: age; sex; how many days per month headache occurs in these 3 months or no headaches; characteristics as (1) unilateral location, (2) pulsating quality, (3) moderate or severe pain intensity, (4) aggravation by or causing avoidance of routine physical activity, and (5) nausea and/or vomiting OR photophobia and phonophobia; the headache duration; what acute medication you use; how many days per month you use the acute medication; use of prophylactic medication for headache; and what prophylactic medication you use (Table 1).

\section{Definition of headache, migraine, and $\mathrm{MOH}$}

In the valid respondents, cases with headaches within the last 3 months were considered chronic headaches. Migraine and $\mathrm{MOH}$ were defined referring to the ICHD-3 [3].

A case of migraine in this study was defined as a respondent, with chronic headache which lasts 4-72 h, who had at least 2 of the characteristics: (1) unilateral location, (2) 
Table 1 Headache questionnaire sheet

\begin{tabular}{ll}
\hline Questions & Answers \\
\hline 1. Age & ( ) y.o \\
2. Sex & Man or Woman \\
3. In these three months, how many days per month does your headache occur? & ( ) days/month \\
4. Does your headache have the following characteristics? & \\
4-1. unilateral location & Yes or No \\
4-2. pulsating quality & Yes or No \\
4-3. moderate or severe pain intensity & Yes or No \\
4-4. aggravation by or causing avoidance of routine physical activity & Yes or No \\
4-5. nausea and/or vomiting OR photophobia and phonophobia & Yes or No \\
5. How long does your headache last? & ( ) hrs or days \\
6-1. What do you use for headaches as acute medication? & (free answer) \\
6-2. How many days per month do you use such acute medication? & ( ) days/month \\
7-1. Do you use prophylactic medication for headaches? & Yes or No \\
7-2. What prophylactic medication do you use? & (free answer) \\
\hline
\end{tabular}

Valid responses were those that filled in all the items in the questionnaire sheet. People who could not understand the questionnaire due to dementia, psychiatric disorder, and mental retardation and who indicated that they did not want to participate in this study were excluded. The questionnaire sheets with one or more blank answers were also excluded from this study pulsating quality, (3) moderate or severe pain intensity, (4) aggravation by or causing avoidance of routine physical activity, and nausea and/or vomiting OR photophobia and phonophobia.

A case of $\mathrm{MOH}$ was defined as a respondent who had headaches $\geq 15$ days per month and reported intake of acetaminophen $\geq 15$ days per month, combination-analgesic (most OTC medicines), or triptan $\geq 10$ days per month. These case definitions approximate Criteria B, C, and D of the ICHD-3 diagnostic criteria for migraine without aura (code 1.1) and Criteria A and B of the ICHD-3 diagnostic criteria for $\mathrm{MOH}$ (code 8.2). Also, chronic headache is defined as having at least 15 headache days per month.

\section{Statistical analysis and clustering by artificial intelligence}

The Shapiro-Wilk test was used to check the normal distribution, and results are shown as median (interquartile range; IQR) for the variables with non-normal distributions. The population proportion test evaluated the prevalence. We then investigated the differences between the $\mathrm{MOH}$ and headache without MO groups. Chi-square or Mann-Whitney U test was performed to compare the 2 groups. Finally, the Kruskal-Wallis test was used to compare the characteristics among the multiple clusters described later. A two-tailed $p<0.0011$ was defined as statistically significant, considering that 45 tests were done (Bonferroni correction 0.05/45).

We performed 2 types of clustering methods to classify the hypothetical subgroups of $\mathrm{MOH}$ patients [18]. We used 8 variables to perform clustering: age, sex, the ordinal scale of headache occurrence per month (15-19 days, 20-24 days,
25-29 days, every day), the characteristics of migraine, the ordinal scale of headache duration (less than $60 \mathrm{~min}, 1-3 \mathrm{~h}$, 4-8 h, 9-24 h, 2-3 days, 4-7 days, over 8 days), the use of combination-analgesic (present or not), the frequency of acute medication oral intake (days), and the use of prophylactic medication (present or not). We first performed hierarchical clustering using the Ward method and described the dendrogram. The number of clusters was decided considering clinical understandability and the shape of the dendrogram. The differences of the variables among each cluster were investigated. We then performed non-hierarchical clustering using $\mathrm{k}-\mathrm{means}++$. The number of clusters was decided using the elbow chart and silhouette score. The differences of variables among each cluster were investigated.

We used SPSS software version 27.0.0. (IBM, New York, USA) for statistical analysis and stratified clustering. Python 3.7.11, scikit-learn 0.24.1, and Matplotlib 3.4.3 for nonstratified clustering and calculating silhouette score.

\section{Ethical aspects}

The study was approved by Itoigawa General Hospital Ethics Committee (approval number 2021-11). The questionnaire was anonymous and did not contain any personally identifiable information. The purpose of the study was explained to the subjects in writing and handed to them. If they were able to participate in the study, they were asked to complete the headache questionnaire. If they were unable or did not want to participate, they were asked to submit a blank sheet of questionnaire or not to receive the questionnaire sheet, thus providing an opportunity for non-participation. All methods were carried out under relevant guidelines and 
regulations (Declaration of Helsinki). All personal patient information was deleted from the database for this study to protect patient privacy.

\section{Results}

\section{Prevalence of headache}

From the 6382 working-age citizens who underwent firsttime vaccination in the 2 large vaccination sites, we acquired 5865 (91.90\%) valid responses, including 2981 men and 2883 women. At the end of July 2021, the overall population of Itoigawa City is 40,822 , and the working-age population is $20,458(50.11 \%)$. This means that we collected the responses from $28.67 \%$ of the working-age population in Itoigawa City.

Among the 5865 respondents, 2407 (41.05\%) reported having experienced headaches in the last 3 months. Migraine was reported by 250 (4.26\%) respondents, and MOH by 136 (2.32\%). The prevalences of chronic headache and migraine peaked at the group aged 30-34 years old, whereas that of $\mathrm{MOH}$ at the group aged $40-44$ years old (Fig. 1a). Women tended to have chronic headache $(68.42 \%)$, migraine (80.80\%), and $\mathrm{MOH}(80.08 \%)$ (Table 2).

\section{Characteristics of $\mathrm{MOH}$}

Of the $136 \mathrm{MOH}$ respondents, $110(80.08 \%)$ were women, and the median age (IQR) was 43 (36-49) years old. Headache occurred 16 (15-20) days per month, and 26 (19.12\%) respondents had migraines. Fifty-five (40.44\%) respondents' headaches last for 9-24 h (Table 3). Of the acute medication, 90 (66.18\%) used combination-analgesic, 60 (44.12\%) used non-opioid analgesic, 5 (3.68\%) used triptan, and 2 $(1.47 \%)$ used opioids as answers to multiple-choice questions (Fig. 1b). The median frequency of acute medication was 15 (10-20) days per month. Ten (7.25\%) of the $\mathrm{MOH}$ respondents used prophylactic medications (Table 3). As the prophylactic medication among the MOH respondents, Japanese kampo medicine, anxiolytic, antihypertensive drugs, eperisone, and low-dose pills were prescribed (Fig. 1c).

Of the $136 \mathrm{MOH}$ patients, the number of estimated $\mathrm{MOH}$ diagnoses were as follows; 4 (2.94\%) triptan-overuse headache (ICHD-3 code 8.2.2), 41 (30.14\%) non-opioid analgesic-overuse headache (code 8.2.3), 68 (50.00\%) combination-analgesic-overuse headache (code 8.2.5), 1 (0.74\%)
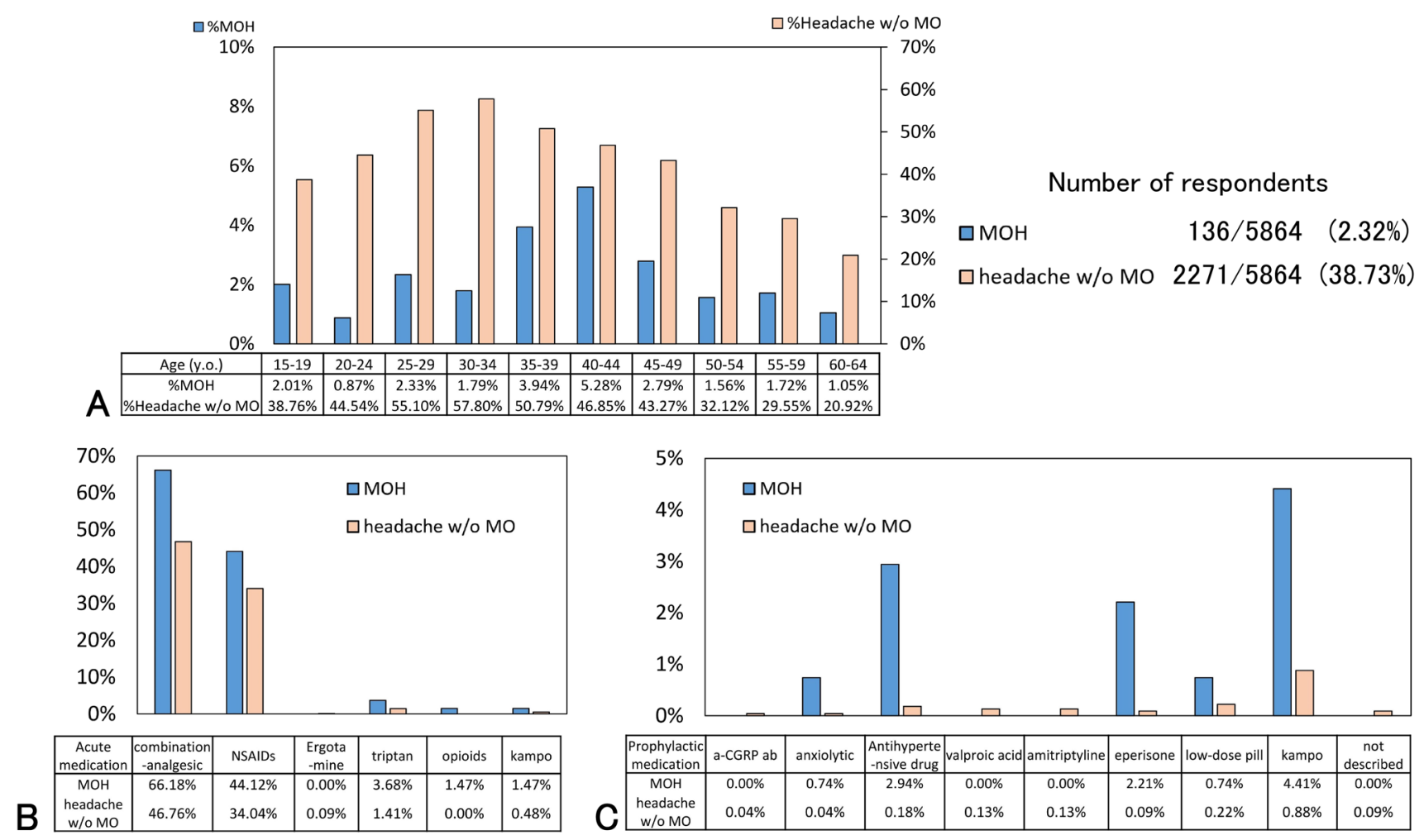

Fig. 1 Age distribution, the proportion of acute and prophylactic medications. (a) Age distribution of $\mathrm{MOH}$ patients and headache patients without MO. (b) The proportion of acute medication among the 2 groups, as answers of multiple-choice questions. (c) The pro- portion of prophylactic medication among the 2 groups as answers of multiple-choice questions. Abbreviations: a-CGRP ab, anti-calcitonin gene-related peptide antibody; $\mathrm{MOH}$, medication-overuse headache; NSAIDs, nonsteroidal anti-inflammatory drugs 


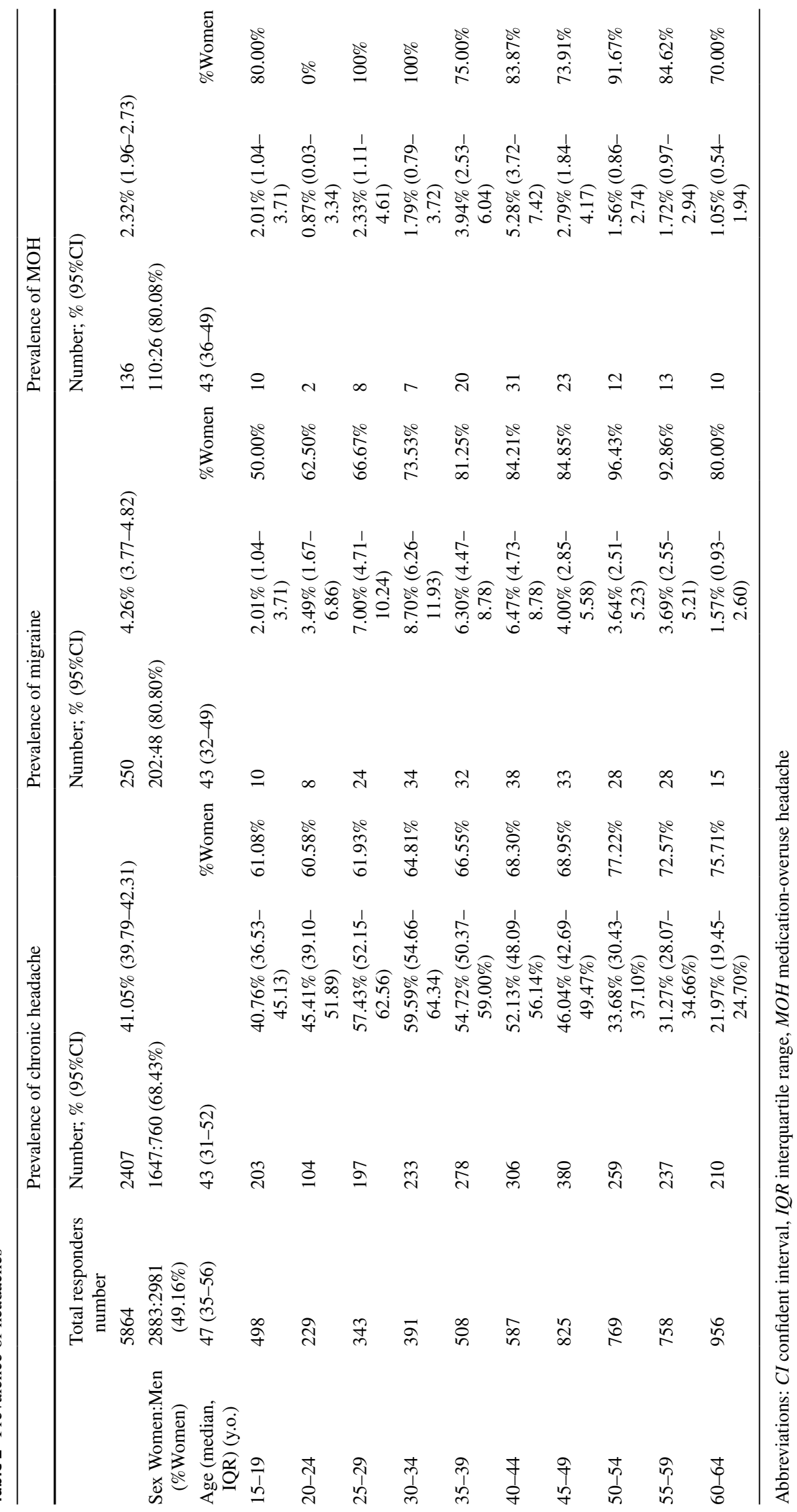


Table 3 Characteristics in $\mathrm{MOH}$ and headache without MO groups

\begin{tabular}{|c|c|c|c|c|c|c|c|c|}
\hline & $\begin{array}{l}\mathrm{MOH} \\
(n=136)\end{array}$ & & $\%(95 \% \mathrm{CI})$ & $\%$ Women & $\begin{array}{l}\text { Headache } \\
\text { without MO } \\
(n=2271)\end{array}$ & $\%(95 \% \mathrm{CI})$ & \%Women & $p$ value $\dagger$ \\
\hline $\begin{array}{l}\text { Age (median, } \\
\text { IQR) (y.o.) }\end{array}$ & $43(36-49)$ & & & & $43(31-51)$ & & & 0.781 \\
\hline $\begin{array}{l}\text { Sex women:men } \\
\text { (\%Women) }\end{array}$ & 110:26 & & & $80.08 \%$ & $1537: 734$ & & $67.86 \%$ & $<0.001 * * *$ \\
\hline $\begin{array}{l}\text { Headache occur- } \\
\text { ring on (days) }\end{array}$ & $16(15-20)$ & & & & $1(1-4)$ & & & $<0.001 * * *$ \\
\hline $\begin{array}{l}\text { Low-frequency } \\
\text { episodic } \\
\text { migraine } \\
\text { (0-3 days/ } \\
\text { month) }\end{array}$ & 0 & $0 \%$ & & & 1498 & $\begin{array}{l}65.96 \%(64.00- \\
67.88)\end{array}$ & $66.28 \%$ & $<0.001 * * *$ \\
\hline $\begin{array}{l}\text { High- } \\
\text { frequency } \\
\text { episodic } \\
\text { migraine } \\
\text { (4-7 days/ } \\
\text { month) }\end{array}$ & 0 & $0 \%$ & & & 510 & $\begin{array}{l}22.45 \%(20.79- \\
24.22)\end{array}$ & $66.27 \%$ & $<0.001 * * *$ \\
\hline $\begin{array}{l}\text { Very high- } \\
\text { frequency epi- } \\
\text { sodic migraine } \\
\text { (8-14 days/ } \\
\text { month) }\end{array}$ & 0 & $0 \%$ & & & 244 & $\begin{array}{l}10.74 \%(9.53- \\
12.09)\end{array}$ & $78.69 \%$ & $<0.001 * * *$ \\
\hline $\begin{array}{l}\text { Chronic } \\
\text { headache } \\
\text { (15-29 days/ } \\
\text { month) }\end{array}$ & 107 & $78.67 \%(71.01-84.77)$ & & $81.30 \%$ & 16 & $0.70 \%(0.42-1.15)$ & $68.75 \%$ & $<0.001 * * *$ \\
\hline Everyday & 29 & $21.32 \%(14.44-28.21)$ & & $79.31 \%$ & 3 & $0.13 \%(0.03-0.41)$ & $100 \%$ & $<0.001 * * *$ \\
\hline \multicolumn{9}{|c|}{ Headache characteristics } \\
\hline $\begin{array}{l}\text { Unilateral loca- } \\
\text { tion }\end{array}$ & 89 & $65.44 \%(57.45-73.43)$ & & $82.02 \%$ & 1389 & $\begin{array}{l}61.16 \%(59.16- \\
63.17)\end{array}$ & $64.00 \%$ & 0.319 \\
\hline $\begin{array}{l}\text { Pulsating qual- } \\
\text { ity }\end{array}$ & 88 & $64.71 \%(56.67-72.74)$ & & $80.68 \%$ & 1281 & $\begin{array}{l}56.41 \%(54.37- \\
58.45)\end{array}$ & $76.11 \%$ & 0.058 \\
\hline $\begin{array}{l}\text { Moderate or } \\
\text { severe pain } \\
\text { intensity }\end{array}$ & 41 & $30.15 \%(22.43-37.86)$ & & $87.80 \%$ & 138 & $6.08 \%(5.09-7.06)$ & $78.99 \%$ & $<0.001 * * *$ \\
\hline $\begin{array}{l}\text { Aggravation } \\
\text { by or causing } \\
\text { avoidance of } \\
\text { routine physi- } \\
\text { cal activity }\end{array}$ & 58 & $42.65 \%(32.33-50.96)$ & & $87.93 \%$ & 376 & $\begin{array}{l}16.56 \%(15.03- \\
18.09)\end{array}$ & $84.04 \%$ & $<0.001 * * *$ \\
\hline $\begin{array}{l}\text { Nausea and/or } \\
\text { vomiting OR } \\
\text { photophobia } \\
\text { and phono- } \\
\text { phobia }\end{array}$ & 42 & $30.88 \%(23.12-38.65)$ & & $83.33 \%$ & 299 & $\begin{array}{l}13.17 \%(11.78- \\
14.56)\end{array}$ & $78.60 \%$ & $<0.001 * * *$ \\
\hline $\begin{array}{l}\text { Probable } \\
\text { migraine }\end{array}$ & 26 & $19.12 \%(12.51-25.73)$ & & $80.77 \%$ & 224 & $\begin{array}{l}9.86 \%(8.64- \\
11.09)\end{array}$ & $80.80 \%$ & $<0.001 * * *$ \\
\hline \multicolumn{9}{|l|}{ Duration } \\
\hline $\begin{array}{l}\text { Less than } \\
60 \text { min }\end{array}$ & 3 & $2.21 \%(0.46-6.57)$ & & $100 \%$ & 64 & $2.82 \%(2.14-3.50)$ & $64.06 \%$ & 0.673 \\
\hline $1-3 \mathrm{~h}$ & 35 & $25.74 \%(18.39-33.08)$ & & $77.14 \%$ & 843 & $\begin{array}{l}37.12 \%(35.13- \\
39.11)\end{array}$ & $63.46 \%$ & 0.007 \\
\hline $4-8 \mathrm{~h}$ & 16 & $11.76 \%(6.35-17.18)$ & & $87.50 \%$ & 300 & $\begin{array}{l}13.21 \%(11.82- \\
14.60)\end{array}$ & $66.33 \%$ & 0.628 \\
\hline
\end{tabular}


Table 3 (continued)

\begin{tabular}{|c|c|c|c|c|c|c|c|}
\hline & $\begin{array}{l}\mathrm{MOH} \\
(n=136)\end{array}$ & $\%(95 \% \mathrm{CI})$ & $\%$ Women & $\begin{array}{l}\text { Headache } \\
\text { without MO } \\
(n=2271)\end{array}$ & $\%(95 \% \mathrm{CI})$ & $\%$ Women & $p$ value $\dagger$ \\
\hline $9-24 \mathrm{~h}$ & 55 & $40.44 \%(32.19-48.69)$ & $78.18 \%$ & 809 & $\begin{array}{l}35.62 \%(33.65- \\
37.59)\end{array}$ & $68.36 \%$ & 0.255 \\
\hline 2-3 days & 11 & $8.09 \%(3.51-12.67)$ & $90.91 \%$ & 242 & $\begin{array}{l}10.66 \%(9.39- \\
11.93)\end{array}$ & $81.82 \%$ & 0.343 \\
\hline 4-7 days & 11 & $8.09 \%(3.51-12.67)$ & $81.82 \%$ & 12 & $0.53 \%(0.23-0.83)$ & $83.33 \%$ & $<0.001 * * *$ \\
\hline Over 8 days & 5 & $3.68 \%(0.51-6.84)$ & $80.00 \%$ & 1 & $0.04 \%(0-0.27)$ & $100 \%$ & $<0.001 * * *$ \\
\hline $\begin{array}{l}\text { Frequency of } \\
\text { acute medication } \\
\text { oral intake (days/ } \\
\text { months) }\end{array}$ & $10(15-20)$ & & & $1(0-3)$ & & & \\
\hline$<1$ days/month & 0 & $0 \%$ & - & 749 & $\begin{array}{l}32.98 \%(31.05- \\
34.91)\end{array}$ & $65.95 \%$ & - \\
\hline $\begin{array}{l}\text { 1-2 days/ } \\
\text { month }\end{array}$ & 0 & $0 \%$ & - & 384 & $\begin{array}{l}16.91 \%(15.37- \\
18.45)\end{array}$ & $73.96 \%$ & - \\
\hline $\begin{array}{l}\text { 3-4 days/ } \\
\text { month }\end{array}$ & 0 & $0 \%$ & - & 388 & $\begin{array}{l}17.08 \%(15.54- \\
18.63)\end{array}$ & $78.35 \%$ & - \\
\hline $\begin{array}{l}\text { 5-9 days/ } \\
\text { month }\end{array}$ & 0 & $0 \%$ & - & 173 & $7.62 \%(6.53-8.71)$ & $82.08 \%$ & - \\
\hline $\begin{array}{l}\text { 10-14 days/ } \\
\text { month }\end{array}$ & 52 & $38.24 \%(30.07-46.40)$ & $80.77 \%$ & 19 & $0.82 \%(0.46-1.21)$ & $84.21 \%$ & - \\
\hline $\begin{array}{l}15-29 \text { days/ } \\
\text { month }\end{array}$ & 60 & $44.12 \%(35.77-52.46)$ & $80.00 \%$ & 0 & - & - & - \\
\hline Everyday & 24 & $17.65 \%(11.24-24.05)$ & $83.33 \%$ & 0 & - & - & - \\
\hline $\begin{array}{l}\text { Use of prophylac- } \\
\text { tic medication }\end{array}$ & 10 & $7.35 \%(2.97-11.74)$ & $90.00 \%$ & 38 & $1.67 \%(1.15-2.20)$ & $81.58 \%$ & $<0.001 * * *$ \\
\hline
\end{tabular}

Abbreviations: $C I$ confident interval, IQR interquartile range, $M O H$ medication-overuse headache, ${ }^{* * *} ; p<0.001$, $\dagger$; Mann-Whitney $\mathrm{U}$ test or Chi-square test was performed

triptan- and combination-analgesic-overuse headache (code 8.2.2 and 8.2.5), and $22(16.18 \%)$ non-opioid analgesicand combination-analgesic-overuse (code 8.2.3 and 8.2.5) (Fig. 1b). The median days of each medication use depending on the MOH subtypes were 15 (10-22.5) for triptanoveruse headache (code 8.2.2), 20 (15-30) for non-opioid analgesic-overuse headache (code 8.2.3), and 15 (10-25) for combination-analgesic-overuse headache (code 8.2.5).

\section{Difference between MOH and headache without MO}

We investigated the difference between $\mathrm{MOH}$ and headache without MO groups. The ratio of women, the frequency of headache, aggravation by or causing avoidance of routine physical activity, moderate or severe pain intensity, nausea and/or vomiting OR photophobia and phonophobia, migraine characteristics, 4 or more days duration, use ratio of combination-analgesic (most OTC medicines), and use ratio of prophylactic medication were all higher in the $\mathrm{MOH}$ group than headache without MO group ( $p<0.001$, all) (Table 3, Figs. 1b and c). The age distribution, the types of acute and prophylactic medications among $\mathrm{MOH}$ patients, and the headache patients without MO are described in Figs. 1a-c.

\section{Clustering results}

The 8 variables (age, sex, the ordinal scale of headache occurrence per month, the characteristics of migraine, the ordinal scale of headache duration, use of combination-analgesic, the frequency of acute medication oral intake, and use of prophylactic medication) were used for the 2 clustering methods.

We first performed hierarchical clustering by the Ward method, and the distance of each case was measured by the square Euclidean distance. The dendrogram is shown in Fig. 2a, and we decided the number of clusters as 3, considering the clinical understandability and the length of the square Euclidean distance. The mean values of each cluster are shown in Table 4. Next, we performed the Kruskal-Wallis test to compare the characteristics of each cluster. The age of cluster 1 was younger than the other 2 clusters (Fig. 2b). The frequency of acute medication oral intake and the ordinal scale of headache occurrence per month was higher in cluster 


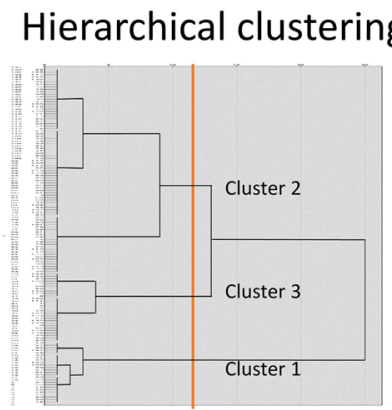

A

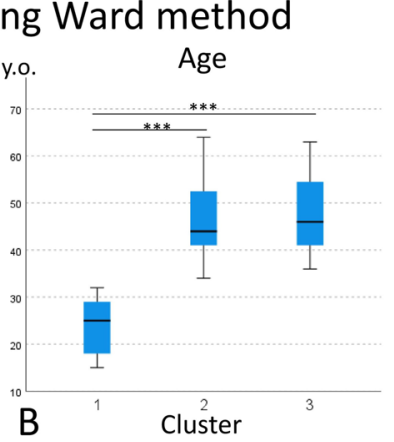

B
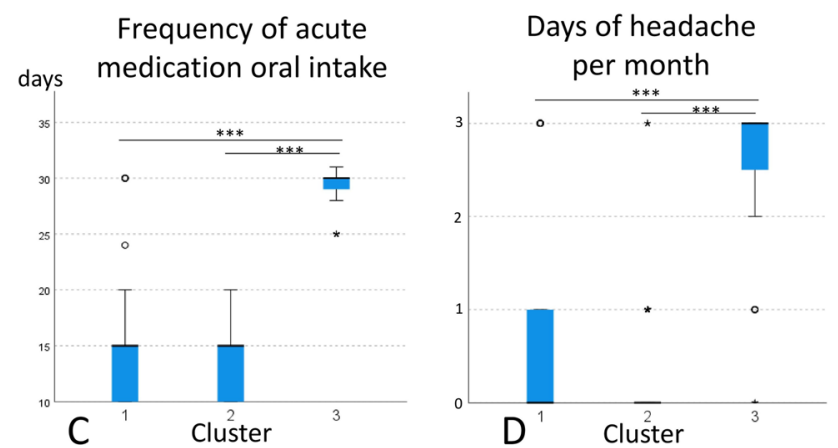

\section{Non-hierarchical clustering using k-means++}

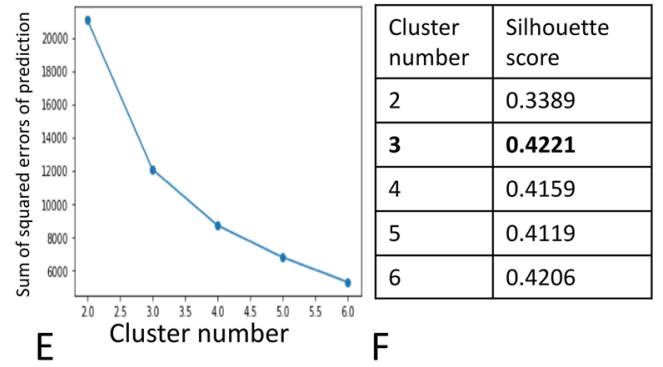

Fig. 2 Results of clustering. (a) Dendrogram by Ward method using square Euclidean distance. The appropriate number of clusters seemed 3, shown in the orange line. (b) The age compared among 3 clusters calculated by Ward method. The age of cluster 1 was younger than the other 2 clusters. (c) The frequency of acute medication oral intake was higher in cluster 3 compared to clusters 1 and 2. (d) The ordinal scale of headache occurrence per month was higher in cluster 3 than in clusters 1 and 2 . The ordinal scale is as follows. 0 , 15-19 days/months; 1, 20-24 days/months; 2, 25-29 days/months; 3,

3 compared to clusters 1 and 2 (Figs. 2c, 2d). Other variables were not statistically different between the 3 clusters (Table 4).

We then performed non-hierarchical clustering using k-means ++ . The elbow chart suggested 3 to 6 is the appropriate number of clusters (Fig. 2e). The silhouette score was calculated, and that of 3 clusters was highest as 0.4221 (Fig. 2f). Therefore, we decided the number of clusters as 3 . The mean values of each cluster are shown in Table 4. Finally, we performed the Kruskal-Wallis test to compare the characteristics of each cluster. The age of cluster 1 was younger than that of cluster 2 , and that of cluster 2 was younger than that of cluster 3 (Fig. 2g). The frequency of acute medication oral intake was higher in cluster 3 compared to clusters 1 and 2, but the $p$ values were not less than 0.001 (Fig. $2 \mathrm{~h}$ ). Other variables were not statistically different between the 3 clusters (Table 4 ).

\section{Discussion}

We report the $\mathrm{MOH}$ prevalence in the working-age population in Itoigawa City, which was $2.32 \%$. We also clarified the difference between $\mathrm{MOH}$ and headache without MO groups. everyday. (e) The elbow chart calculated by k-means ++ , suggesting 3 to 6 is the appropriate number of clusters. (f) The silhouette score was calculated, and that of 3 clusters was highest as 0.4221 . (g) The age compared among 3 clusters calculated by k-means ++ . The age of cluster 1 was younger than that of cluster 2 , and that of cluster 2 was younger than that of cluster 3. (h) The frequency of acute medication oral intake seemed higher in cluster 3 compared to clusters 1 and 2. Abbreviations: y.o., years old; *, $p<0.050$; **, $p<0.010$; ***, $p<0.001$

We besides hypothesized that the MOH respondents could be grouped into 3 clusters: (1) low aged and moderately frequent use of acute medication, (2) middle-aged and moderately frequent use of acute medication, and (3) relatively older and more frequent use of acute medication.

\section{MOH prevalence}

The MOH prevalence is reported as 1-2\% worldwide [14], but it depends on the country and study design. Our study is the first report on the $\mathrm{MOH}$ prevalence in the general Japanese population. However, the respondents' ages were limited to 15-64 years old, so the careful interpretation of results needed similar to the previous epidemiological reports. MOH is prevalent in women and middle-aged [19], and our results seemed similar.

The recent survey from Denmark revealed that the most commonly overused medication was paracetamol (41.5\%), and combination-analgesic (25.3\%), ibuprofen (21.9\%), opioids (17.0\%), and triptans (9.1\%) were also overused [20]. The frequency of use for drugs implicated in $\mathrm{MOH}$ varies from country to country and is influenced by multiple factors 
Table 4 Means of each variable among clusters

\begin{tabular}{|c|c|c|c|c|c|c|}
\hline \multicolumn{7}{|l|}{ Hierarchical clustering using Ward method } \\
\hline & Total & Cluster 1 & Cluster 2 & Cluster 3 & $\begin{array}{l}\text { Kruskal- } \\
\text { Wallis test } \\
\text { or Chi- } \\
\text { squared } \\
\text { test }\end{array}$ & Mann-Whitney U test or Chi-squared test \\
\hline Number & 136 & 25 & 83 & 28 & & \\
\hline Age (y.o.) & 42.49 & 23.8 & 46.3 & 47.89 & $<0.001 * * *$ & $1<3,2 ; p<0.001$ all $* * *$ \\
\hline Sex: Women is 1 & 0.80 & 0.80 & 0.80 & 0.84 & 0.867 & - \\
\hline Headache frequency $\dagger$ & 0.81 & 0.84 & 0.23 & 2.50 & $<0.001 * * *$ & $1,2<3 ; p<0.001$ all $* * *$ \\
\hline Migraine is 1 & 0.19 & 0.17 & 0.17 & 0.28 & 0.137 & - \\
\hline Duration $\neq$ & 2.62 & 2.48 & 2.52 & 3.04 & 0.256 & - \\
\hline Use of combination-analgesic is 1 & 0.67 & 0.57 & 0.72 & 0.68 & 0.043 & $p>0.050$ all \\
\hline $\begin{array}{l}\text { Frequency of acute medication oral intake } \\
\text { (days/months) }\end{array}$ & 17.08 & 15.36 & 13.53 & 29.14 & $<0.001 * * *$ & $2,1<3 ; p<0.001$ all $* * *$ \\
\hline Use of prophylactic medication is 1 & 0.07 & 0.11 & 0.06 & 0.040 & 0.272 & - \\
\hline \multicolumn{7}{|c|}{ Non-hierarchical clustering using k-means ++} \\
\hline & Total & Cluster 1 & Cluster 2 & Cluster 3 & $\begin{array}{l}\text { Kruskal- } \\
\text { Wallis test } \\
\text { or Chi- } \\
\text { squared } \\
\text { test }\end{array}$ & Mann-Whitney U test or Chi-squared test \\
\hline Number & 136 & 25 & 65 & 46 & & \\
\hline Age (y.o.) & 42.49 & 23.80 & 41.31 & 54.33 & $<0.001 * * *$ & $1<2<3 ; p<0.001$ all $* * *$ \\
\hline Sex: Women is 1 & 0.80 & 0.84 & 0.80 & 0.80 & 0.907 & - \\
\hline Headache frequency $\dagger$ & 0.81 & 0.84 & 0.54 & 1.17 & 0.055 & - \\
\hline Migraine is 1 & 0.19 & 0.28 & 0.17 & 0.17 & 0.457 & - \\
\hline Duration $\neq$ & 2.62 & 2.48 & 2.62 & 2.70 & 0.827 & - \\
\hline Use of combination-analgesic is 1 & 0.67 & 0.68 & 0.72 & 0.57 & 0.218 & - \\
\hline $\begin{array}{l}\text { Frequency of acute medication oral intake } \\
\text { (days/months) }\end{array}$ & 17.08 & 15.36 & 15.74 & 19.91 & $<0.001 * * *$ & $\begin{array}{l}1,2<3 \\
p=0.021 \text { for } 1 \text { vs } 3^{*} \\
p=0.005 \text { for } 2 \text { vs } 3^{* *}\end{array}$ \\
\hline Use of prophylactic medication is 1 & 0.07 & 0.04 & 0.06 & 0.11 & 0.500 & - \\
\hline
\end{tabular}

$* ; p<0.050, * * ; p<0.010 * * * ; p<0.001, \dagger$; Ordinal scale for headache frequency as follows. $0 ; 15-19$ days/months, $1 ; 20-24$ days/months, 2; 25-29 days/months, 3; everyday, ¥; Ordinal scale for headache duration as follows. 0; less than $60 \mathrm{~min}, 1$; 1-3 h; 2; 4-8 h, 3; 9-24 h, 4; 2-3 days, 5; 4-7 days, 6; over 8 days

and the era [21]. In this study, combined-analgesic (most OTC medicines) and non-opioid analgesic (loxoprofen or acetaminophen) were widely used in Itoigawa City. In Japan, most OTC analgesics are combinations of two or more nonsteroidal anti-inflammatory drugs with caffeine. Also, opioids are not covered by national insurance for chronic headaches. Therefore, the use of combination-analgesic as OTC medicines and non-opioid analgesic (loxoprofen and acetaminophen, commonly prescribed drugs) might relate to $\mathrm{MOH}$ in Japan. In addition, since few physicians might be familiar with headache treatment, so triptans were not widely prescribed.

Previously, habitual smoking, low physical activity [19], low income, and low educational level [22] were reported as risk factors for $\mathrm{MOH}$ development. However, we did not ask about such items, so we could not investigate the trends.
Therefore, we performed clustering to get insight from the questionnaire results from other perspectives, described later.

\section{Difference between MOH and headache without MO groups}

In our results, more women suffered $\mathrm{MOH}$, and $\mathrm{MOH}$ had characteristics of aggravation by or causing avoidance of routine physical activity, moderate or severe pain intensity, nausea and/or vomiting OR photophobia and phonophobia, and migraine. An episodic headache disorder typically precedes the development of $\mathrm{MOH}$, usually migraine or tension-type headache, that has been treated with frequent and excessive amounts of acute symptomatic medications [14, 23]. MOH's characteristics in our study are directly related 
to daily life and socioeconomic activities. Although it is a matter of speculation, many working-age women are coping with OTC analgesics, and inappropriate overuse may lead to MOH development. Especially, 56\% [24] of working women in Japan are non-regular employees and have difficulty taking time off work, considering the possibility of being fired. Therefore, it might relate to analgesic-overuse for women's headaches. In Denmark, the national awareness campaign for $\mathrm{MOH}$ is succeeded, resulting in an increase in the percentage of the public who knew about MOH (from 31 to 38\%) [25]. In Japan, awareness-raising activities on $\mathrm{MOH}$ and other headache knowledge are also needed, and efforts to reduce their negative socioeconomic impact are necessary.

\section{MOH despite the use of prophylactic medication}

Of the $136 \mathrm{MOH}$ respondents, 10 (7.35\%) used prophylactic medication from doctors, and the prophylactic medication use ratio is higher in $\mathrm{MOH}$ group than headache without MO group. This suggested, considering the presence of 5 triptan-overuse headache respondents, that there is a lack of appropriate headache treatment by physicians engaged in primary headache care and that there were some chronic headache patients refractory to prophylactic medications.

$\mathrm{MOH}$ is thought to be dichotomized into 2 types, simple type and complex type, to develop better treatment strategies and outcome measuring tools [26]. The definition of 2 types differs according to the researchers, but the simple type would refer to relatively uncomplicated cases, such as patients just overusing non-opioid medication. Our study suggests that $\mathrm{MOH}$ with insufficient prophylactic medication or refractory against prophylactic medication can be recognized as complex type, similar to the previous reports [27]. Recent monoclonal antibodies targeting the calcitonin generelated peptide seem effective in refractory chronic migraine patients with $\mathrm{MOH}$, so it is necessary to continue raising awareness for both clinicians and patients about the socioeconomic importance of headaches and new treatment of monoclonal antibodies targeting the calcitonin gene-related peptide [28].

\section{Clustering}

Clustering is the division of a set of classification objects into subsets so that internal cohesion and external isolation are achieved, providing insight into the differences in patients' phenotypes, independent of existing diagnoses (unsupervised learning). There are 3 previous reports using the clustering method. Bruehl [29] confirmed the correspondence of the diagnoses according to the criteria of the International Headache Society (IHS) with statistically derived clusters using k-means. On the other hand, Rokicki [30] suggested that the IHS classification system appears to lack adequate specificity and sensitivity for college-aged students with headaches who report migraine-like symptoms. He suggested that the migraine-like students could be further divided into two types statistically. Therefore, statistical clustering can suggest new patient subtypes from a different perspective than existing clinical subtyping. Mazzotta [31] used k-means to classify pictures drawn by children with headaches, leading to good non-verbal headache assessment. Clustering can statistically group such complex and multidimensional variables into some clusters.

In our study, we performed the Ward method and k-means ++ to group the $\mathrm{MOH}$ patients into 3 clusters: (1) low aged and moderately frequent use of acute medication, (2) middle-aged and moderately frequent use of acute medication, and (3) relatively older and more frequent use of acute medication. Existing subtype definition according to the overused-medication [3], simple type or complex type [26], and risk factors [19, 22] is of course useful. However, we suggest that there are 3 types of $\mathrm{MOH}$ depending on age and frequency of acute medication use. Although it is a matter of speculation, we may categorize $\mathrm{MOH}$ into three types: young people who have just started working and experienced severe stress specific to the young workers [32], middle-aged people who are busy with both work and childrearing, and the older probably with mild cognitive disorder or anxiety who uses frequent analgesic. The older also tend to have common comorbidities like other pain syndromes, sleep-related disorders, and gastrointestinal disorders, which aggravate migraine, supposedly leading to $\mathrm{MOH}$ development [33]. Given the social background where developing $\mathrm{MOH}$, classification based on age and frequency of medication may be an important perspective. In addition, if such social backgrounds are different, then treatment approaches may need to be different. Further research on subtypes from different perspectives is desirable.

\section{Limitation}

First, this study was performed in a rural city in Japan, and the respondents covered about $30 \%$ of the actual workingage population. Itoigawa City does not yet have adequate resources for neurological and headache care, and the prevalence may vary compared to urban areas with more medical resources in Japan. The evidence for this is supported by the low prescription rate of triptans and prophylactic medications, compared to the previous Japanese survey describing that $36.2 \%$ of migraine patients were taking prescription medication to treat or prevent migraine [8]. Second, we performed this questionnaire at the 2 large vaccination sites, so we could not evaluate the citizens who did not come to the vaccination site or who selected other vaccination sites. Third, we did not investigate the MOH prevalence of preadolescents, children [34], and the elderly over 65 years old 
$[35,36]$. Fourth, $\mathrm{MOH}$ is diagnosed after filling a prospective 3-month headache diary. Our study investigated retrospectively, so the diagnosis should be interpreted carefully. Fifth, the 3 clusters in this study were hypothetically and mathematically decided, so the clinical meanings of each cluster should be carefully interpreted. A further large study on $\mathrm{MOH}$ prevalence all over Japan is needed.

\section{Conclusions}

$\mathrm{MOH}$ prevalence among the working-age population in Itoigawa is $2.32 \%$. Combined-analgesic (most OTC medicines) and non-opioid analgesic (loxoprofen or acetaminophen) were widely overused. More women suffered $\mathrm{MOH}$, and $\mathrm{MOH}$ had characteristics of aggravation by or causing avoidance of routine physical activity, moderate or severe pain intensity, and migraine, compared to headache without MO. Of the $136 \mathrm{MOH}$ respondents, 10 (7.35\%) used prophylactic medication from doctors, but their headaches might not be well-controlled. We performed the Ward method and $\mathrm{k}$-means + + to group the $136 \mathrm{MOH}$ patients into 3 clusters. Age and frequency of acute medication use may be important for subtype grouping from a social perspective apart from existing clinical subtypes.

Acknowledgements We are thankful for the medical staff and servant services to support our work and data acquisition.

Funding This research did not receive any specific grant from funding agencies in the public, commercial, or not-for-profit sectors.

\section{Declarations}

Competing interests The authors report no conflicts of interest concerning the materials or methods used in this study or the findings presented in this paper. No sources of financial nor material supported were given. This article and contents of this study were not published nor presented previously.

\section{References}

1. Jensen R, Stovner LJ (2008) Epidemiology and comorbidity of headache. Lancet Neurol 7:354-361. https://doi.org/10.1016/ S1474-4422(08)70062-0

2. Vos T, Lim SS, Abbafati C et al (2020) Global burden of 369 diseases and injuries in 204 countries and territories, 1990-2019: a systematic analysis for the Global Burden of Disease Study 2019. Lancet 396:1204-1222. https://doi.org/10.1016/S0140-6736(20) 30925-9

3. No authors listed (2018) Headache Classification Committee of the International Headache Society (IHS) The International Classification of Headache Disorders, 3rd edition. Cephalalgia 38:1-211. https://doi.org/10.1177/0333102417738202

4. Matsumori Y, Ueda K, Komori M et al (2021) Burden of Migraine in Japan: Results of the ObserVational Survey of the Epidemiology, tReatment, and Care Of MigrainE (OVERCOME [Japan]) Study. Neurol Ther. https://doi.org/10.1007/ s40120-021-00305-9

5. Takeshima T, Ishizaki K, Fukuhara Y et al (2004) Populationbased door-to-door survey of migraine in Japan: The Daisen Study. Headache J Head Face Pain 44:8-19. https://doi.org/10. 1111/j.1526-4610.2004.04004.x

6. Sakai F, Igarashi H (1997) Prevalence of migraine in Japan: A nationwide survey. Cephalalgia 17:15-22. https://doi.org/10. 1046/j.1468-2982.1997.1701015.x

7. Chronic Headache Clinical Practice Guideline Development Committee (2015) Clinical Practice Guideline for Chronic Headache 2013. https://www.neurology-jp.org/guidelinem/ch/ index.html. Accessed 20 Sept 2021

8. Kikui S, Chen Y, Todaka H et al (2020) Burden of migraine among Japanese patients: a cross-sectional National Health and Wellness Survey. J Headache Pain 21:110. https://doi.org/10. 1186/s10194-020-01180-9

9. Suzuki N, Ishikawa Y, Gomi S et al (2014) Prevalence and characteristics of headaches in a socially active population working in the Tokyo metropolitan area -surveillance by an industrial health consortium. Intern Med 53:683-689. https://doi.org/10. 2169/internalmedicine.53.1700

10. Okuma H, Kitagawa Y (2005) [Epidemiology of headache] (Japanese). Nippon rinsho Japanese J Clin Med 63:1705-1711. https://doi.org/10.1177/033310240102100708

11. Jonsson P, Hedenrud T, Linde M (2011) Epidemiology of medication overuse headache in the general Swedish population. Cephalalgia 31:1015-1022. https://doi.org/10.1177/03331 02411410082

12. Vos T, Abajobir AA, Abate KH et al (2017) Global, regional, and national incidence, prevalence, and years lived with disability for 328 diseases and injuries for 195 countries, 1990-2016: a systematic analysis for the Global Burden of Disease Study 2016. Lancet 390:1211-1259. https://doi.org/10.1016/S0140-6736(17)32154-2

13. Rapoport AM (2008) Medication overuse headache. Awareness, detection and treatement. CNS Drugs 22:995-1004. https://doi. org/10.2165/0023210-200822120-00003

14. Diener H-C, Dodick D, Evers S et al (2019) Pathophysiology, prevention, and treatment of medication overuse headache. Lancet Neurol 18:891-902. https://doi.org/10.1016/S1474-4422(19) 30146-2

15. Viana M, De Icco R, Allena M et al (2019) Clinical subtypes of medication overuse headache - Findings from a large cohort. Headache J Head Face Pain 59:1481-1491. https://doi.org/10. 1111/head.13641

16. Ward JH Jr (1963) Hierarchical grouping to optimize an objective function. J Am Stat Assoc 58:236-244

17. Arthur D, Vassilvitskii S (2007) k-means++: The advantages of careful seeding. SODA '07

18. Ishimura S, Ishimura K (2021) [Procedure for multivariate data analysis using SPSS] (Japanese), 6th ed. Tokyo Tosho, Tokyo

19. Westergaard ML, Glümer C, Hansen EH, Jensen RH (2014) Prevalence of chronic headache with and without medication overuse: Associations with socioeconomic position and physical and mental health status. Pain 155:2005-2013. https://doi.org/10.1016/j. pain.2014.07.002

20. Westergaard ML, Lau CJ, Allesøe K et al (2020) Monitoring chronic headache and medication-overuse headache prevalence in Denmark. Cephalalgia 40:6-18. https://doi.org/10.1177/03331 02419876909

21. Diener H-C, Limmroth V (2004) Medication-overuse headache: a worldwide problem. Lancet Neurol 3:475-483. https://doi.org/ 10.1016/S1474-4422(04)00824-5

22. Atasoy HT, Unal AE, Atasoy $\mathrm{N}$ et al (2005) Low income and education levels may cause medication overuse and chronicity in 
migraine patients. Headache J Head Face Pain 45:25-31. https:// doi.org/10.1111/j.1526-4610.2005.05006.x

23. Thorlund K, Sun-Edelstein C, Druyts E et al (2016) Risk of medication overuse headache across classes of treatments for acute migraine. J Headache Pain 17:107. https://doi.org/10.1186/ s10194-016-0696-8

24. Gender Equality Bureau Cabinet Office G (2021) [2020 White Paper on Gender Equality (Summary Version)] in Japanese. https://www.gender.go.jp/about_danjo/whitepaper/r02/gaiyou/ index.html. Accessed 19 Oct 2021

25. Carlsen LN, Westergaard ML, Bisgaard M et al (2018) National awareness campaign to prevent medication-overuse headache in Denmark. Cephalalgia 38:1316-1325. https://doi.org/10.1177/ 0333102417736898

26. Da Silva AN, Lake AE (2014) Clinical aspects of medication overuse headaches. Headache J Head Face Pain 54:211-217. https:// doi.org/10.1111/head.12223

27. Hepp Z, Dodick DW, Varon SF et al (2015) Adherence to oral migraine-preventive medications among patients with chronic migraine. Cephalalgia 35:478-488. https://doi.org/10.1177/03331 02414547138

28. Lambru G, Hill B, Murphy M et al (2020) A prospective real-world analysis of erenumab in refractory chronic migraine. J Headache Pain 21:61. https://doi.org/10.1186/s10194-020-01127-0

29. Bruehl S, Lofland KR, Semenchuk EM et al (1999) Use of cluster analysis to validate IHS diagnostic criteria for migraine and tension-type headache. Headache J Head Face Pain 39:181-189. https://doi.org/10.1046/j.1526-4610.1999.3903181.x

30. Rokicki LA, Semenchuk EM, Bruehl S et al (1999) An examination of the validity of the IHS classification system for migraine and tension-type headache in the college student population. Headache J Head Face Pain 39:720-727. https://doi.org/10.1046/j. 1526-4610.1999.3910720.x

31. Mazzotta S, Pavlidis E, Cordori C et al (2015) Children's headache: Drawings in the diagnostic work up. Neuropediatrics 46:261-268. https://doi.org/10.1055/s-0035-1550147

32. Sawang S, Newton CJ (2018) Defining work stress in young people. J Employ Couns 55:72-83. https://doi.org/10.1002/joec. 12076

33. Altamura C, Corbelli I, de Tommaso M et al (2021) Pathophysiological bases of comorbidity in migraine. Front Hum Neurosci 15:640574. https://doi.org/10.3389/fnhum.2021.640574

34. Genc D, Vaičienė-Magistris N, Zaborskis A et al (2021) The burden attributable to headache disorders in children and adolescents in Lithuania: estimates from a national schoolsbased study. J Headache Pain 22:24. https://doi.org/10.1186/ s10194-021-01237-3

35. Wang S-J, Fuh J-L, Lu S-R et al (2000) Chronic daily headache in Chinese elderly: Prevalence, risk factors, and biannual follow-up. Neurology 54:314-314. https://doi.org/10.1212/WNL.54.2.314

36. Katsuki M, Kawamura S, Kashiwagi K, Koh A (2021) Medication overuse headache successfully treated by Japanese herbal kampo medicine, yokukansan. Cureus 13:8-11. https://doi.org/10.7759/ cureus. 18326

Publisher's note Springer Nature remains neutral with regard to jurisdictional claims in published maps and institutional affiliations. 